\title{
Centrifugal acceleration in the magnetotail lobes
}

\author{
H. Nilsson ${ }^{1}$, E. Engwall ${ }^{2,3}$, A. Eriksson ${ }^{3}$, P. A. Puhl-Quinn ${ }^{4}$, and S. Arvelius ${ }^{1}$ \\ ${ }^{1}$ Swedish Institute of Space Physics, Kiruna, Sweden \\ ${ }^{2}$ Department of Physics and Astronomy, Uppsala University, Uppsala, Sweden \\ ${ }^{3}$ Swedish Institute of Space Physics, Uppsala, Sweden \\ ${ }^{4}$ Space Science Center, University of New Hampshire, Durham, NH, USA
}

Received: 11 September 2009 - Revised: 2 February 2010 - Accepted: 10 February 2010 - Published: 15 February 2010

\begin{abstract}
Combined Cluster EFW and EDI measurements have shown that cold ion outflow in the magnetospheric lobes dominates the hydrogen ion outflow from the Earth's atmosphere. The ions have too low kinetic energy to be measurable with particle instruments, at least for the typical spacecraft potential of a sunlit spacecraft in the tenuous lobe plasmas outside a few $R_{\mathrm{E}}$. The measurement technique yields both density and bulk velocity, which can be combined with magnetic field measurements to estimate the centrifugal acceleration experienced by these particles. We present a quantitative estimate of the centrifugal acceleration, and the velocity change with distance which we would expect due to centrifugal acceleration. It is found that the centrifugal acceleration is on average outward with an average value of about of $5 \mathrm{~m} \mathrm{~s}^{-2}$. This is small, but acting during long transport times and over long distances the cumulative effect is significant, while still consistent with the relatively low velocities estimated using the combination of EFW and EDI data. The centrifugal acceleration should accelerate any oxygen ions in the lobes to energies observable by particle spectrometers. The data set also put constraints on the effectiveness of any other acceleration mechanisms acting in the lobes, where the total velocity increase between 5 and $19 R_{\mathrm{E}}$ geocentric distance is less than $5 \mathrm{~km} \mathrm{~s}^{-1}$.
\end{abstract}

Keywords. Magnetospheric physics Magnetosphereionosphere interactions

\section{Introduction}

Solar wind interaction with a planetary atmosphere involves exchange of both mass and energy. Energy and solar wind origin particles are transferred to the uppermost layers of the

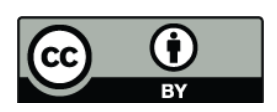

Correspondence to: H. Nilsson (hans.nilsson@irf.se) atmosphere, and atmospheric origin particles may be transferred into interplanetary space. For magnetized planets, such as Earth, reconnection between the planetary and solar wind magnetic fields opens up a path for effective energy transfer from the solar wind to the ionosphere, as well as a direct escape path for the atmospheric origin plasma. Whereas the magnetic field of Earth can be said to protect the low latitude atmosphere from the solar wind, the interaction is rather amplified in the cusp and polar cap region. This is most clearly evident in the ionospheric projection of the magnetospheric cusp, the region of most direct entry of solar wind mass and energy into the magnetosphere. In the ionospheric projection of the cusp the solar wind origin precipitation leads to ionospheric upflow which can be directly observed by incoherent scatter radar (Nilsson et al., 1996; Ogawa et al., 2003). This upflow is still gravitationally bound and further heating is necessary in order to overcome gravity. Such heating due to wave particle interaction is common in the cusp and mantle region at a large range of altitudes (Andersson et al., 2005; Bouhram et al., 2004; Arvelius et al., 2005; Nilsson et al., 2006). Nilsson et al. (2008b) suggested that further heating above the ionosphere is common enough that the number flux observed at higher altitude is modulated by the ionospheric upflow. The cusp upflow represents a source rich in oxygen. It is much more difficult to tell how much of the protons observed in the cusp originated in the ionosphere and how much of the outflowing ions are reflected solar wind origin protons. Theoretically an outflow of cold light ions (i.e. mainly protons) is expected on the open field lines of the polar cap. This outflow is named the polar wind in analogy with the solar wind (Axford, 1968; Banks and Holzer, 1968). The polar wind does not have the coupling to the cusp transients as do the oxygen outflow, and is expected to show less transients. The polar wind is at least initially cold enough that with suitable instrumentation it may be distinguished from solar wind origin proton fluxes. The polar wind has been confirmed and

Published by Copernicus Publications on behalf of the European Geosciences Union. 
quantified by observations from several spacecraft at different altitudes (Hoffman and Dodson, 1980; Nagai et al., 1984; Cully et al., 2003a; Moore et al., 1997). Based on the initial conditions provided by the observations several models predict that the high latitude outflow continues into the lobes, to either feed the plasma sheet or escape (Chappell et al., 2000; Cully et al., 2003b). The fate of the outflowing ions is critically dependent on the further field-aligned acceleration during the transport through the magnetosphere. Faster ions escape and slower ions end up in the plasma sheet and are returned to the near Earth space (where they may still be lost to interplanetary space, but that is another story).

Several populations of different species and different energy are thus of interest to understand both planetary atmospheric loss due to solar wind interaction and magnetospheric dynamics. One particularly difficult population to measure is the cold proton plasma in the lobes. These protons may have a significant flux while still not enough energy to be observable by particle spectrometers, due to the significant positive potential of a sunlit spacecraft in a tenuous plasma. This observational difficulty has been overcome by a recently introduced technique described by Engwall et al. (2006a). In brief the method uses the fact that for suitable conditions an enhanced wake is formed around the positively charged spacecraft. The wake disturbs the electric field measurements by the Cluster double probe experiment (Gustafsson et al., 2001). By comparing the electric field measurement signature of the wake with a model, the flow velocity can be determined. The wake does not disturb the electron drift instrument EDI (Paschmann et al., 2001), which can be used to determine the perpendicular $(\boldsymbol{E} \times \boldsymbol{B})$ plasma flow, making a decomposition of the plasma flow into its parallel and perpendicular parts possible. The density can be estimated from the spacecraft potential, so that the field-aligned flux of plasma can be determined. By applying this new method Engwall et al. (2009b) could show that cold proton fluxes dominates in the distant lobes, out to $19 R_{\mathrm{E}}$ geocentric distance. Fluxes likely to escape were of the same order of magnitude as most reports from lower altitudes, i.e. of the order of $10^{26} \mathrm{~s}^{-1}$. This means that most of the cold plasma eventually escape. It was also found that cold proton outflow constitute a major part of the net proton outflow from the Earth.

A question which arises is how cold plasma can dominate in large portions of the magnetosphere, given the many heating and acceleration processes which are known to occur. For the cold plasma outflow in the lobes the most likely acceleration mechanism is the centrifugal acceleration. Cladis (1986) studied the centrifugal acceleration of $\mathrm{O}^{+}$ions during transport from the polar ionosphere to the plasma sheet. As a first approximation one can expect protons to obtain a similar acceleration (the centrifugal acceleration being mass independent, but part of the centrifugal acceleration, as well as the time available for acceleration, is dependent on the parallel velocity of the particles which may vary for different populations). Nilsson et al. (2008a) have calculated the centrifu- gal acceleration of outflowing ions in the high altitude (5$12 R_{\mathrm{E}}$ geocentric distance) polar cap/mantle. The study used four-spacecraft Cluster magnetometer measurements to estimate the gradient of the magnetic field, and Cluster ion spectrometer (Rème et al., 2001) ion measurements to estimate the parallel and perpendicular ion velocities, thus obtaining all terms determining the centrifugal acceleration from direct measurements. The purpose of this paper is to apply the same technique to another region of the Earth's magnetosphere and another data set, the cold ion outflow in the lobes. We will thus for the first time get a quantitative assessment of centrifugal acceleration in the lobes. Furthermore the estimate of the centrifugal acceleration will show if the outflow velocities derived with the new technique of Engwall et al. (2006a) and reported in Engwall et al. (2009a,b) is consistent with the centrifugal acceleration calculated for the same data set.

\section{Method}

We make use of Cluster spacecraft data from the electric field and wave instrument (EFW, Gustafsson et al., 2001), the electron drift instrument (EDI, Paschmann et al., 2001) and the fluxgate magnetometer (FGM, Balogh et al., 2001). We combine the analysis method and data set used by Engwall et al. (2009a,b) with the method to estimate centrifugal acceleration used by Nilsson et al. (2008a).

\subsection{Estimating cold proton fluxes using the wake method}

The wake method is based on measurements from two different electric field instruments on Cluster. The Cluster EFW instrument is sensitive to the electric field resulting from an enhanced wake arising behind a positively charged spacecraft in a cold tenuous plasma. The direction of the wake gives the direction of the outflow. The outflow velocity can be calculated using a model of the wake formation.

A wake forms behind any spacecraft in a supersonic flow, i.e. when $m v_{\mathrm{i}}^{2} / 2>K T_{\mathrm{i}}$, where $m v_{\mathrm{i}} / 2$ is the ion bulk drift energy, $T_{\mathrm{i}}$ is the ion temperature and $K$ Boltzmann's constant. The wake charges negatively, as electrons rarely are supersonic and hence easily enter the wake. In tenuous magnetospheric plasmas, the Debye length is typically large compared to the spacecraft size, so a wake of transverse size set by the spacecraft dimensions will charge to only a fraction of $K T_{\mathrm{e}} / e$. However, if in addition the spacecraft potential is much higher than the ion bulk drift energy equivalent, ions scatter off the spacecraft electrostatic field and create a much bigger wake, called an enhanced wake, which can charge to order $K T_{\mathrm{e}} / e$. Such a wake thus forms if

$K T_{\mathrm{i}}<\frac{m v_{\mathrm{i}}^{2}}{2}<e V_{\mathrm{sc}}$

where $e V_{\mathrm{sc}}$ is the energy corresponding to the spacecraft potential and all other variables as defined above. The 
accumulation of electrons in the wake will, for the case when the wake is sufficiently large due to the positive spacecraft potential, create an appreciable local wake electric field close to the spacecraft. The probes of the EFW instrument are separated by $88 \mathrm{~m}$, which is suitable for detection of the wake field. This effect has been verified by particle-in-cell simulations by Engwall et al. (2006b). The EDI instrument, which is based on a technique which measures the drift of artificially emitted $0.5-1 \mathrm{keV}$ electrons as they gyrate back to the spacecraft, is not sensitive to the wake electric field. This is because in the lobes the gyro radius of the EDI electrons is several $\mathrm{km}$, while the wake length scale is on the order of $100 \mathrm{~m}$. The wake electric field can thus be estimated as $E^{\mathrm{w}}=E^{\mathrm{EFW}}-E^{\mathrm{EDI}}$ and can be used to derive the flow velocity of the ions. The ions are unmagnetized on the wake length scale, which means that the wake electric field is in the flow direction. Combining the total flow direction with the perpendicular flow velocity given by EDI and the magnetic field estimate from FGM we can thus obtain also the parallel velocity. We refer to Engwall et al. (2006a, 2009a) for details on the derivation of the ion velocity through the wake method, but provide the formula for the parallel velocity below:

$u_{\|}=\frac{E_{x}^{\mathrm{w}} u_{\perp, y}-E_{y}^{\mathrm{w}} u_{\perp, x}}{E_{y}^{\mathrm{w}} \boldsymbol{B}_{x}-E_{x}^{\mathrm{w}} \boldsymbol{B}_{y}} \boldsymbol{B}$

Subindices $x$ and $y$ refer to two measured components in the spin plane, $E^{\mathrm{w}}$ is the wake electric field, $\boldsymbol{B}$ is the magnetic field and $u_{\perp}$ is the perpendicular drift estimated using EDI.

The method limitations are that (1) EDI data must exist, (2) measurements are not possible when the active spacecraft potential is active (Torkar et al., 2001), (3) the wake must not be completely perpendicular to the spin plane, (4) it is not possible to detect cold ions coexisting with hot plasma, since the hot ions will fill the wake and cancel the wake electric field, and (4) it cannot distinguish between different ion species. However $\mathrm{H}^{+}$ions are expected to dominate the low energy ion outflow (Su et al., 1998), and for the calculated velocities $\mathrm{O}^{+}$ions would frequently have a higher drift energy than the spacecraft potential. For details on the error analysis of the data set we refer to Engwall et al. (2009a).

\subsection{Estimating centrifugal acceleration from four- spacecraft data}

The centrifugal acceleration of charged particles moving along magnetic field lines in the presence of a finite convection electric field is

$$
\frac{d V_{\|}}{d t}=\boldsymbol{V}_{\mathbf{E}} \cdot \frac{d \hat{\boldsymbol{b}}}{d t}=\boldsymbol{V}_{\mathbf{E}} \cdot\left(\frac{\partial \hat{\boldsymbol{b}}}{\partial t}+V_{\|} \frac{\partial \hat{b}}{\partial \boldsymbol{s}}+\left(V_{\mathrm{E}} \cdot \nabla\right) \hat{\boldsymbol{b}}\right)
$$

where $V_{\|}$is the field-aligned (parallel) velocity of the particle, $V_{\mathrm{E}}$ is the $\boldsymbol{E} \times \boldsymbol{B}$ drift, $\boldsymbol{s}$ is a vector along the magnetic field direction and $\hat{\boldsymbol{b}}$ is the unit vector in the direction of the magnetic field (Northrop, 1963; Cladis, 1986). In subsequent discussions we will refer to the three terms in the bracket on the right hand side of Eq. (3) as the temporal term (the $\frac{\partial \hat{b}}{\partial t}$ term), the parallel term (dependent on $V_{\|}$) and the perpendicular term. The perpendicular and temporal terms of the centrifugal acceleration depends on the $\boldsymbol{E} \times \boldsymbol{B}$ drift and the spatial and temporal change of the magnetic field direction respectively. These parameters are the same for all particles regardless of initial energy. These terms can thus be expected to be particularly important for cold ion outflow.

The first order spatial gradient of the magnetic field can be estimated from four-spacecraft data except when all spacecraft are in the same plane. The measurements provide four spatial data points for each vector component of the magnetic fields. Thus an equation can be formed (for the $\mathrm{x}$-component as an example) as:

$\frac{d \boldsymbol{B}_{\mathrm{x}}}{d x} \Delta x_{31}+\frac{d \boldsymbol{B}_{\mathrm{x}}}{d y} \Delta y_{31}+\frac{d \boldsymbol{B}_{\mathrm{x}}}{d z} \Delta z_{31}=\Delta \boldsymbol{B}_{\mathrm{x} 31}$

where $\boldsymbol{B}_{\mathrm{X}}$ is the magnetic field $\mathrm{x}$-component, $\Delta x_{31}$ indicates the difference in position along $x$ between spacecraft 3 and $1\left(x_{1}-x_{3}\right)$ and $\Delta \boldsymbol{B}_{\mathrm{x} 31}$ indicates the difference in the magnetic field $\mathrm{x}$-component as measured at spacecraft 1 and 3 $\left(\boldsymbol{B}_{\mathrm{xsc} 1}-\boldsymbol{B}_{\mathrm{xsc} 3}\right)$. The same equation can be formed for spacecraft 2 and 4 as well (keeping spacecraft 3 as reference spacecraft). A $3 \times 3$ matrix can then be formed and the $\frac{d \boldsymbol{B}_{\mathrm{X}}}{d r}$ components can be solved for using standard inverse matrix methods, given that the four spacecraft are not coplanar. The same system of equations can then be solved for the gradients of the $\boldsymbol{B}_{\mathrm{y}}$ and $\boldsymbol{B}_{\mathrm{z}}$ components. This way of solving for the gradient of the magnetic field and its limitations are discussed in Harvey (1998).

\section{Results}

We have used the same data set as Engwall et al. (2009a), except that data points without valid estimates of the centrifugal acceleration are not included. The distribution of the values of the centrifugal acceleration terms as described in Sect. 2.2 are shown in Fig. 1.

Red bars in the histograms indicate outward acceleration, light grey bars indicate inward acceleration, i.e. deceleration of outflow. The top panel shows the acceleration due to the parallel term, the middle panel the acceleration due to the perpendicular term and the bottom panel the acceleration due to the temporal term. The centrifugal acceleration is fairly small, mostly in the span 1 to $10 \mathrm{~m} \mathrm{~s}^{-2}$. For the temporal term the net average is close to zero, acceleration is about as common as deceleration as could be expected. For the other terms outward acceleration dominates. We will thus ignore the temporal term, as it will not yield an appreciable error in the calculation of the total average acceleration of outflowing ions. The distribution of the total centrifugal acceleration is shown in Fig. 1 panel (d). When the different terms are 
(a)

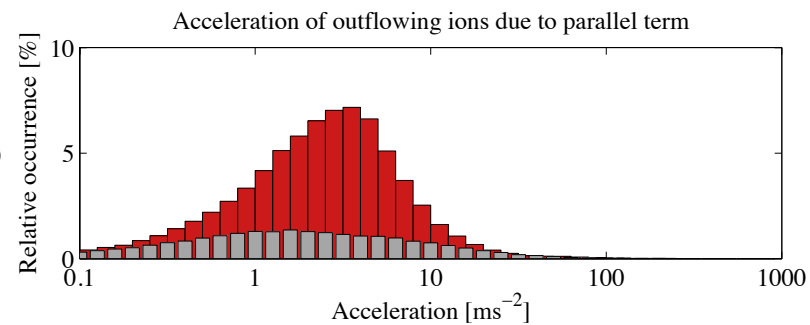

(b)

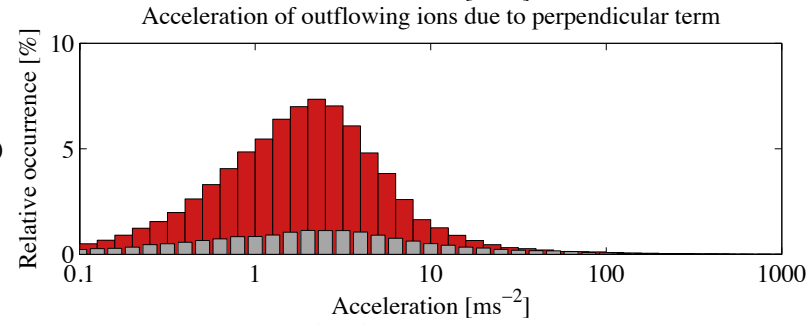

(c)

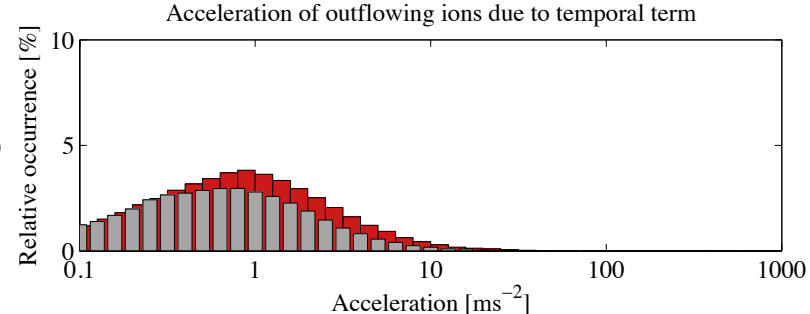

(d)

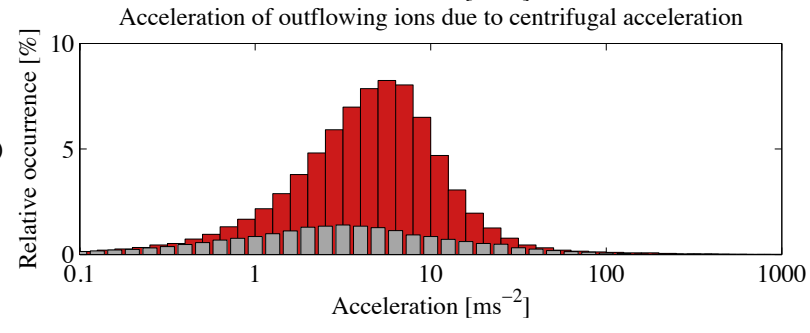

Fig. 1. Distribution of the centrifugal acceleration for all valid measurement points. The $\mathrm{x}$-axis shows the acceleration $\left[\mathrm{m} \mathrm{s}^{-2}\right]$, the $y$-axis shows the relative occurrence [\%] for positive (increased outflow velocity, red bars) and negative acceleration (decreased outflow velocity, light grey bars). The light grey bars are shifted half a bin towards lower values to increase readability. Panel (a) shows the parallel term, (b) the perpendicular term, (c) the temporal term of Eq. (3). Panel (d) shows the sum of all terms.

added, the peak is still between 1 and $10 \mathrm{~m} \mathrm{~s}^{-2}$, but we see a shift towards higher centrifugal acceleration as the different components add up constructively.

One of the important points of the Engwall et al. (2009b) report was that cold flowing ions are observed all the way out to $19 R_{\mathrm{E}}$ geocentric distance. We therefore plot the average centrifugal acceleration as a function of geocentric distance in Fig. 2, panel (a). We have removed outliers with centrifugal acceleration above $100 \mathrm{~m} \mathrm{~s}^{-2}$ to get averages representative of the vast majority of measurement points (see distribution in Fig. 1, panel d). The $\mathrm{X}$-axis shows the geocentric distance in Earth radii $\left(R_{\mathrm{E}}\right)$, and the $\mathrm{y}$-axis the average outward centrifugal acceleration in $\mathrm{m} \mathrm{s}^{-2}$. We can see that
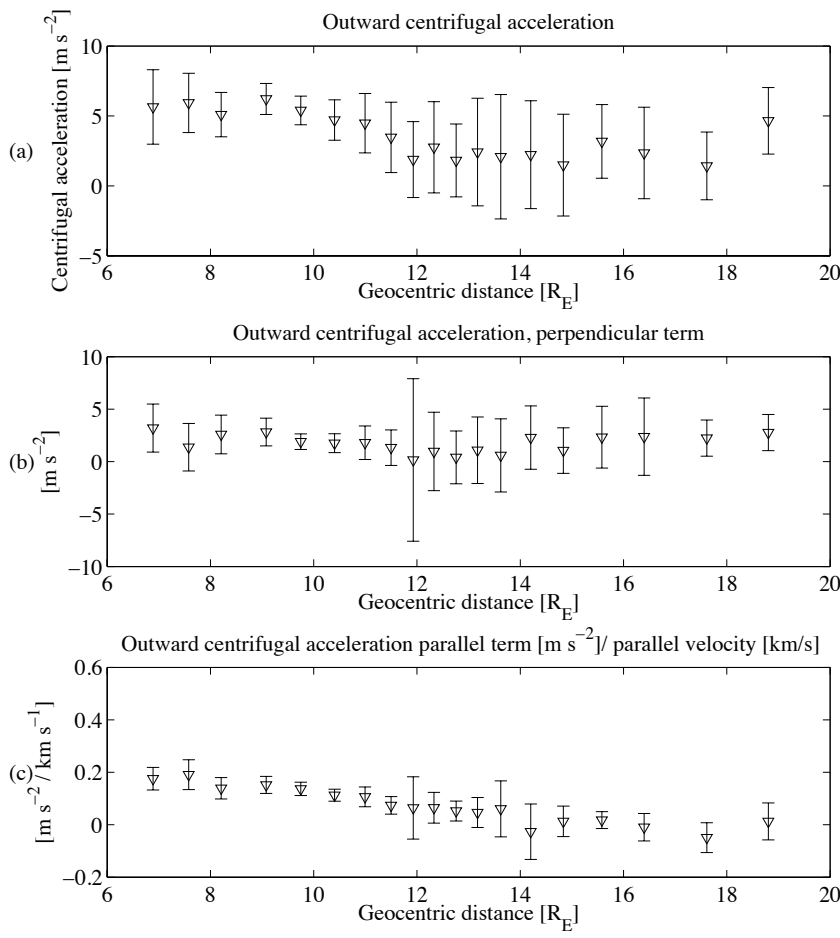

Fig. 2. Panel (a) shows the distribution of the centrifugal acceleration as function of the geocentric distance. Panel (b) shows the average centrifugal acceleration due to the perpendicular term $\left[\mathrm{m} \mathrm{s}^{-2}\right]$. Panel (c) shows the average of the parallel centrifugal acceleration term divided by the parallel velocity $\left[\mathrm{m} \mathrm{s}^{-2} /\left(\mathrm{km} \mathrm{s}^{-1}\right)\right]$. The $\mathrm{x}$-axis show the geocentric distance $\left[R_{\mathrm{E}}\right]$. Error bars indicate $95 \%$ confidence level for normal distributed data, based on both variance of orbit average values and variance of all measurement points.

the average centrifugal acceleration is around $5 \mathrm{~m} \mathrm{~s}^{-2}$, falling off with geocentric distance, which is expected due to the decreasing curvature of the geomagnetic field with geocentric distance.

The data is binned into bins with an equal amount of data points, about 9000 data points per bin. For the error bars we have assumed that there is variability on two time scales, on the measurement point to measurement point basis and on an orbit to orbit basis. The error bars are thus based on the variance of the data points in each bin and the variance of the average value for each orbit contributing data to the bin. For the confidence interval the standard deviation for these two measures of variability are divided by the square root of the number of data points and the square root of the number of orbits contributing to data in each bin respectively. The orbit to orbit variability have the smallest number of samples thus providing the main contribution to the uncertainty. We then indicate with error bars the $95 \%$ confidence interval for normal distributed data. We use the same technique to establish a confidence interval for all parameters we present in the subsequent figures. 
Is the average centrifugal acceleration as function of distance consistent with the resulting parallel velocity as function of distance reported in Engwall et al. (2009a)? To judge that we must take into account the travel time of the particles so that we can calculate a velocity resulting from the observed acceleration. The travel time depends on the parallel velocity, which will in turn affect the parallel term of the centrifugal acceleration. We need therefore split our average centrifugal acceleration into a perpendicular term, which is the same for all particles, and a parallel term which depends on the parallel velocity. The parallel term is linearly dependent on the parallel velocity so we can calculate an average parallel term divided by the parallel velocity. This new term can be used together with the parallel velocity of a test particle to calculate the resulting centrifugal acceleration due to the parallel term. We show both the perpendicular term and the part of the parallel term without the parallel velocity in Fig. 2, panels (b) and (c), respectively. Note that for simplicity the unit for the parallel velocity is $\mathrm{km} \mathrm{s}^{-1}$. As can be seen Fig. 2 panel (b) the perpendicular term is rather constant with distance.

Using the data shown in Fig. 2, panels (b) and (c), we can now start test particles at the beginning of our measurement interval $\left(5 R_{\mathrm{E}}\right)$ and let them experience the average centrifugal acceleration within each bin of our data set. The final result will depend on the initial value, as slower particles will have more time to be accelerated by the perpendicular term. Faster particles will experience more acceleration due to the parallel term, but for a shorter time. The increase in parallel term acceleration is offset by the decrease in time and will thus be the same per distance travelled for all particles. The parallel velocity as function of geocentric distance which results from such a calculation, together with the observed average parallel velocity for each bin is shown in Fig. 3. Black lines show calculated parallel velocities for different initial velocities at $5 R_{\mathrm{E}}$, whereas red circles with error bars show the average observed parallel velocities. As can be expected the range of calculated velocities decrease, slow particles have a longer time to experience acceleration so with time the range of velocities converge. Agreement between observations and calculation is rather good, at least out to a distance of about $14 R_{\mathrm{E}}$, and our confidence intervals are essentially within the range of calculated values. Note that some values are excluded because of lack of valid estimates of the centrifugal acceleration, therefore our results are slightly different from those presented by Engwall et al. (2009a), but the differences are well within our confidence limits.

In Fig. 3 we also show the same results for the cusp outflow discussed in Nilsson et al. (2008a), with solid black lines for the calculated values, and black circles with error bars for the data. The locations where the different data were taken are shown in a small figure inserted in the top right of Fig. 3, with black dots representing data from the Nilsson et al. (2008a) study, and red dots representing data from

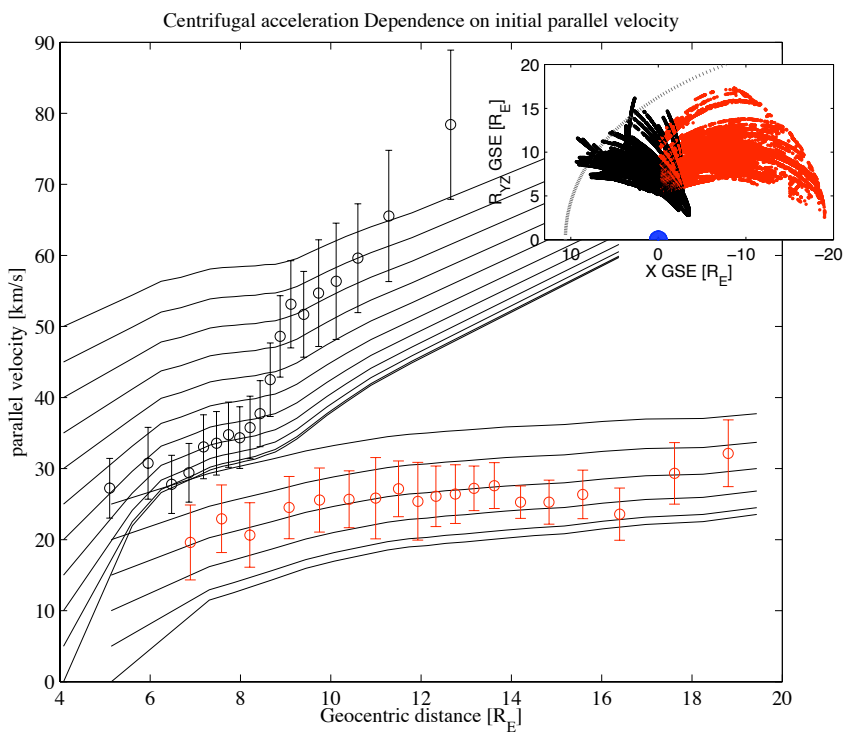

Fig. 3. Parallel velocity as function of the geocentric distance. The $\mathrm{x}$-axis shows the geocentric distance $\left[R_{\mathrm{E}}\right]$, the $\mathrm{y}$-axis shows the parallel velocity as observed in the lobe region (red circles with error bars) and for the cusp/mantle ion outflow (black circles with error bars). Velocities resulting from average observed centrifugal acceleration as function of different initial values at $5 R_{\mathrm{E}}$ (lobes) and $4 R_{\mathrm{E}}$ (cusp/mantle) are shown with solid black lines. Error bars indicate $95 \%$ confidence level for normal distributed data, based on both variance of orbit average values and variance of all measurement points. Inserted in the top right of the main figure is a figure indicating where the data was taken in $\mathrm{X}, R=\sqrt{Y^{2}+Z^{2}}$ coordinates $\left[R_{\mathrm{E}}\right]$, black dots for the cusp/mantle and red dots for lobe data points (i.e. from this study).

this study. A cylindrical coordinate system was used, with location in $\mathrm{X}$ and $R=\sqrt{Y^{2}+Z^{2}}$ coordinates. For the Nilsson et al. (2008a) study GSE coordinates were used, in this study GSM coordinates were used. A model magnetopause (the model of Shue et al. (1998), $\boldsymbol{B}_{\mathrm{Z}}=-5 \mathrm{nT}, n=5 \mathrm{~cm}^{-3}$ and $V_{\mathrm{sw}}=350 \mathrm{~km} \mathrm{~s}^{-1}$ ) is shown with a dotted gray line. Earth is indicated by a blue ball. One can clearly see that the centrifugal acceleration is stronger in the region geometrically above the polar cap than in the lobes (which maps magnetically to the polar cap). Furthermore there seems to be another acceleration mechanism operating in the $8-10 R_{\mathrm{E}}$ geocentric distance cusp/mantle region - this is effective transverse heating leading through the mirror force to increased outflow velocities (Nilsson et al., 2006). The altitude region where this acceleration is seen is in part an effect of the Cluster orbit, sampling the poleward part of the cusp below about $8 R_{\mathrm{E}}$ geocentric distance, and having more complete coverage above. This does not affect the conclusion that there are other acceleration mechanisms affecting the parallel velocity for the high altitude cusp/mantle path. There is no corresponding region of obvious acceleration in addition to the centrifugal acceleration in the lobe outflow. The total velocity increase 
over the measurement range is about $15 \mathrm{~km} \mathrm{~s}^{-1}$. To remain within our $95 \%$ confidence interval the increase can be between about 0 and $20 \mathrm{~km} \mathrm{~s}^{-1}$. Centrifugal acceleration adds between 15 and $20 \mathrm{~km} \mathrm{~s}^{-1}$ (somewhat less with high initial velocity, but a high initial velocity leaves even less room for any additional acceleration). This leaves at most $5 \mathrm{~km} \mathrm{~s}^{-1}$ as total velocity increase due to other mechanisms such as field-aligned potential drops, transverse heating and ambipolar diffusion.

\section{Discussion and conclusions}

Centrifugal acceleration in the lobes is found to be quite small, typically in the range of $1-10 \mathrm{~m} \mathrm{~s}^{-2}$. It is still of some importance because very slow particles will experience acceleration for a long time. We can therefore expect an increase of the average parallel velocity with geocentric distance, just as is observed. The velocities resulting from the centrifugal acceleration calculated using ion velocity and magnetic field gradients are consistent with the observed velocities. It is thus clear that centrifugal acceleration of cold plasma in the lobes does not accelerate protons to drift energies where we would expect them to be observable with particle spectrometers. Oxygen ions on the other hand, which would experience the same acceleration due to centrifugal acceleration as protons, would be observable for most circumstances. From Fig. 3 we can see that we can expect parallel velocities of above $10 \mathrm{~km} \mathrm{~s}^{-1}$, typically 15 to $20 \mathrm{~km} \mathrm{~s}^{-1}$. This in addition to a perpendicular drift which is 15 to $20 \mathrm{~km} \mathrm{~s}^{-1}$ (not shown here, but total velocity is shown in Engwall et al., 2009a). This is still typically well below 5 $\mathrm{eV}$ for protons but oxygen ions with the same velocity have a 16 times higher drift energy. So whereas the new method of Engwall et al. (2006a) have discovered a previously hidden population of protons in the lobes, our results indicate that particle detectors would be able to detect oxygen ions if there is an appreciable amount of them.

Our results concerns ions observed beyond a geocentric distance of $5 R_{\mathrm{E}}$. What about the first part of the transport, from the ionosphere and above the polar cap? The study by Cladis (1986) reported simulations of the centrifugal acceleration of $\mathrm{O}^{+}$ions for the entire transport path from the ionosphere to the plasma sheet. For the region where their model overlaps with our measurement region the $\mathrm{O}^{+}$energy range is $50-110 \mathrm{eV}$ (see their Figs. 1 and 2). This corresponds to $\mathrm{H}^{+}$energies of $3-7 \mathrm{eV}$ for the same velocities of $24-37 \mathrm{~km} \mathrm{~s}^{-1}$. This in turn is in good agreement with our average value of $26 \mathrm{~km} \mathrm{~s}^{-1}$ (Engwall et al., 2009a). At about $5 R_{\mathrm{E}}$ geocentric distance along trajectories that reach far into the tail, and therefore into our measurement region (i.e. their trajectories 1 and 2), the $\mathrm{O}^{+}$energy is of the order of $10 \mathrm{eV}$. This corresponds to a velocity of $10 \mathrm{~km} \mathrm{~s}^{-1}$ which is also consistent with our results. One may also note that outflowing $\mathrm{O}^{+}$emanating from the ionospheric projection of the cusp, observed at altitudes well below $5 R_{\mathrm{E}}$ are typically of the order of $10 \mathrm{~km} \mathrm{~s}^{-1}$ or more so that they are expected to be within the particle detector energy range already before the centrifugal acceleration in the lobes (e.g. Strangeway et al., 2005; Bouhram et al., 2004). This would then correspond to a high initial velocity in our Fig. 3 .

Our main conclusions are:

1. Centrifugal acceleration in the magnetotail lobes is small, but when acting over long time it results in velocity increases of up to $20 \mathrm{~km} \mathrm{~s}^{-1}$ from 5 to $19 R_{\mathrm{E}}$.

2. Centrifugal acceleration in the lobes is more important for slower particles than for faster particles, since the slower particles are subject to the centrifugal acceleration for a longer time.

3. Engwall et al. (2009a,b) showed that the cold outflowing ions have low energy throughout the lobes. The current study shows that centrifugal acceleration is consistent with the low observed parallel velocity, and also that centrifugal acceleration can explain the total observed velocity increase from 5 to $19 R_{\mathrm{E}}$. This puts strong limits on any additional acceleration mechanisms in the lobes, such as field-aligned potential drops, ambipolar diffusion or distributed heating, which can add less than $5 \mathrm{~km} \mathrm{~s}^{-1}$ between 5 and $19 R_{\mathrm{E}}$.

4. For most conditions the centrifugal acceleration in the lobes should be strong enough to accelerate $\mathrm{O}^{+}$to energies observable by ion spectrometers. We note here that other processes at lower altitudes are expected to already have brought the $\mathrm{O}^{+}$ions emanating from the polar cusp region into the ion spectrometer measurement range, centrifugal acceleration will further add to this.

Our results can be particularly valuable when coupled with numerical simulation models of the ion flow in the lobes. Such models can incorporate further acceleration due to ambipolar diffusion and wave heating along the ion flight path. Our results give an observational constraint (less than $5 \mathrm{~km} \mathrm{~s}^{-1}$ between 5 and $19 R_{\mathrm{E}}$ ) on the efficiency of any such additional acceleration mechanisms. Electric and magnetic field data is available from the Cluster data, and a future study of the wave fields in the lobes could be interesting in the context of our findings. However, our data set does not contain the temperature of the plasma, strongly limiting the possibility to estimate the wave heating. Even if waves are present we cannot know if they are effective in heating the ions if we do not have ion temperature estimates.

Acknowledgements. The work of $\mathrm{HN}$ was supported by the Swedish Research Council.

Topical Editor I. A. Daglis thanks two anonymous referees for their help in evaluating this paper. 


\section{References}

Andersson, L., Peterson, W. K., and McBryde, K. M.: Estimates of the suprathermal $\mathrm{O}^{+}$outflow characteristic energy and relative location in the auroral oval, Geophys. Res. Lett., 32, L09104, doi:10.1029/2004GL021434, 2005.

Arvelius, S., Yamauchi, M., Nilsson, H., Lundin, R., Hobara, Y., Rème, H., Bavassano-Cattaneo, M.B., Paschmann, G., Korth, A., Kistler, L. M., and Parks, G. K.: Statistics of high-altitude and high-latitude O+ ion outflows observed by Cluster/CIS, Ann. Geophys., 23, 1909-1916, 2005,

http://www.ann-geophys.net/23/1909/2005/.

Axford, W. I.: The Polar Wind and the Terrestrial Helium Budget, J. Geophys. Res., 73, 6855-6859, doi:10.1029/JA073i021p06855, 1968.

Balogh, A., Carr, C. M., Acuña, M. H., Dunlop, M. W., Beek, T. J., Brown, P., Fornacon, K.-H., Georgescu, E., Glassmeier, K.H., Harris, J., Musmann, G., Oddy, T., and Schwingenschuh, K.: The Cluster Magnetic Field Investigation: overview of in-flight performance and initial results, Ann. Geophys., 19, 1207-1217, 2001 ,

http://www.ann-geophys.net/19/1207/2001/.

Banks, P. M. and Holzer, T. E.: The Polar Wind, J. Geophys. Res., 73, 6846-6854, doi:10.1029/JA073i021p06846, 1968.

Bouhram, M., Klecker, B., Miyake, W., Rème, H., Sauvaud, J.-A., Malingre, M., Kistler, L., and Blăgău, A.: On the altitude dependence of transversely heated $\mathrm{O}^{+}$distributions in the cusp/cleft, Ann. Geophys., 22, 1787-1798, 2004,

http://www.ann-geophys.net/22/1787/2004/.

Chappell, C. R., Giles, B. L., Moore, T. E., Delcourt, D. C., Craven, P. D., and Chandler, M. O.: The adequacy of the ionospheric source in supplying magnetospheric plasma, J. Atmos. SolarTerr. Phys., 62, 421-436, doi:10.1016/S1364-6826(00)00021-3, 2000.

Cladis, J. B.: Parallel acceleration and transport of ions from polar ionosphere to plasmasheet, J. Geophys. Res., 13, 893-896, 1986.

Cully, C. M., Donovan, E. F., Yau, A. W., and Arkos, G. G.: Akebono/Suprathermal Mass Spectrometer observations of lowenergy ion outflow: Dependence on magnetic activity and solar wind conditions, J. Geophys. Res. (Space Physics), 108, 1093, doi:10.1029/2001JA009200, 2003a.

Cully, C. M., Donovan, E. F., Yau, A. W., and Opgenoorth, H. J.: Supply of thermal ionospheric ions to the central plasma sheet, J. Geophys. Res. (Space Physics), 108, 1092, doi:10.1029/ 2002JA009457, 2003b.

Engwall, E., Eriksson, A. I., André, M., Dandouras, I., Paschmann, G., Quinn, J., and Torkar, K.: Low-energy (order $10 \mathrm{eV}$ ) ion flow in the magnetotail lobes inferred from spacecraft wake observations, Geophys. Res. Lett., 33, 6110, doi:10.1029/ 2005GL025179, 2006a.

Engwall, E., Eriksson, A. I., and Forest, J.: Wake formation behind positively charged spacecraft in flowing tenuous plasmas, Phys. Plasmas, 13, 062904, doi:10.1063/1.2199207, 2006b.

Engwall, E., Eriksson, A. I., Cully, C. M., André, M., Puhl-Quinn, P. A., Vaith, H., and Torbert, R.: Survey of cold ionospheric outflows in the magnetotail, Ann. Geophys., 27, 3185-3201, 2009a, http://www.ann-geophys.net/27/3185/2009/.

Engwall, E., Eriksson, A. I., Cully, C. M., André, M., Torbert, R., and Vaith, H.: Earth's ionospheric outflow dominated by hidden cold plasma, Nature Geosci., 2, 24-27, 2009b.
Gustafsson, G., André, M., Carozzi, T., Eriksson, A. I., Flthammar, C.-G., Grard, R., Holmgren, G., Holtet, J. A., Ivchenko, N., Karlsson, T., Khotyaintsev, Y., Klimov, S., Laakso, H., Lindqvist, P.-A., Lybekk, B., Marklund, G., Mozer, F., Mursula, K., Pedersen, A., Popielawska, B., Savin, S., Stasiewicz, K., Tanskanen, P., Vaivads, A., and Wahlund, J.-E.: First results of electric field and density observations by Cluster EFW based on initial months of operation, Ann. Geophys., 19, 1219-1240, 2001 , http://www.ann-geophys.net/19/1219/2001/.

Harvey, C. C.: Analysis Methods for Multi-spacecraft data, chap. 12, pp. 307-322, ISSI Scientific report SR-001, ESA Publications Division, 1998.

Hoffman, J. H. and Dodson, W. H.: Light ion concentrations and fluxes in the polar regions during magnetically quiet times, J. Geophys. Res., 85, 626-632, doi:10.1029/JA085iA02p00626, 1980.

Moore, T. E., Chappell, C. R., Chandler, M. O., Craven, P. D., Giles, B. L., Pollock, C. J., Burch, J. L., Young, D. T., Waite Jr., J. H., Nordholt, J. E., Thomsen, M. F., McComas, D. J., Berthelier, J. J., Williamson, W. S., Robson, R., and Mozer, F. S.: Highaltitude observations of the polar wind., Science, 277, 349-351, doi:10.1126/science.277.5324.349, 1997.

Nagai, T., Waite Jr., J. H., Green, J. L., Chappell, C. R., Olsen, R. C., and Comfort, R. H.: First measurements of supersonic polar wind in the polar magnetosphere, Geophys. Res. Lett., 11, 669-672, doi:10.1029/GL011i007p00669, 1984.

Nilsson, H., Yamauchi, M., Eliasson, L., Norberg, O., and Clemmons, J.: The ionospheric signature of the cusp as seen by incoherent scatter radar, J. Geophys. Res., 101, 10947-10963, 1996.

Nilsson, H., Waara, M., Arvelius, S., Marghitu, O., Bouhram, M., Hobara, Y., Yamauchi, M., Lundin, R., Rème, H., Sauvaud, J.A., Dandouras, I., Balogh, A., Kistler, L. M., Klecker, B., Carlson, C. W., Bavassano-Cattaneo, M. B., and Korth, A.: Characteristics of high altitude oxygen ion energization and outflow as observed by Cluster: a statistical study, Ann. Geophys., 24, 1099-1112, 2006, http://www.ann-geophys.net/24/1099/2006/.

Nilsson, H., Waara, M., Marghitu, O., Yamauchi, M., Lundin, R., Rème, H., Sauvaud, J.-A., Dandouras, I., Lucek, E., Kistler, L. M., Klecker, B., Carlson, C. W., Bavassano-Cattaneo, M. B., and Korth, A.: An assessment of the role of the centrifugal acceleration mechanism in high altitude polar cap oxygen ion outflow, Ann. Geophys., 26, 145-157, 2008a, http://www.ann-geophys.net/26/145/2008/.

Nilsson, H., Waara, M., Marghitu, O., Yamauchi, M., Lundin, R., Rème, H., Sauvaud, J.-A., Dandouras, I., Lucek, E., Kistler, L. M., Klecker, B., Carlson, C. W., Bavassano-Cattaneo, M. B., and Korth, A.: Transients in oxygen outflow above the polar cap as observed by the Cluster spacecraft, Ann. Geophys., 26, 33653373, 2008b, http://www.ann-geophys.net/26/3365/2008/.

Northrop, T. G.: The adiabatic motion of charged particles, Interscience Publishers, N.Y., 1963.

Ogawa, Y., Fujii, R., Buchert, S. C., Nozawa, S., and Ohtani, S.: Simultaneous EISCAT Svalbard radar and DMSP observations of ion upflow in the dayside polar ionosphere, J. Geophys. Res., 108, 1101, doi:10.1029/2002JA009590, 2003.

Paschmann, G., Quinn, J. M., Torbert, R. B., Vaith, H., McIlwain, 
C. E., Haerendel, G., Bauer, O. H., Bauer, T., Baumjohann, W., Fillius, W., Förster, M., Frey, S., Georgescu, E., Kerr, S. S., Kletzing, C. A., Matsui, H., Puhl-Quinn, P., and Whipple, E. C.: The Electron Drift Instrument on Cluster: overview of first results, Ann. Geophys., 19, 1273-1288, 2001, http://www.ann-geophys.net/19/1273/2001/.

Rème, H., Aoustin, C., Bosqued, J. M., Dandouras, I., Lavraud, B., Sauvaud, J. A., Barthe, A., Bouyssou, J., Camus, Th., CoeurJoly, O., Cros, A., Cuvilo, J., Ducay, F., Garbarowitz, Y., Medale, J. L., Penou, E., Perrier, H., Romefort, D., Rouzaud, J., Vallat, C., Alcaydé, D., Jacquey, C., Mazelle, C., d'Uston, C., Möbius, E., Kistler, L. M., Crocker, K., Granoff, M., Mouikis, C., Popecki, M., Vosbury, M., Klecker, B., Hovestadt, D., Kucharek, H., Kuenneth, E., Paschmann, G., Scholer, M., Sckopke, N., Seidenschwang, E., Carlson, C. W., Curtis, D. W., Ingraham, C., Lin, R. P., McFadden, J. P., Parks, G. K., Phan, T., Formisano, V., Amata, E., Bavassano-Cattaneo, M. B., Baldetti, P., Bruno, R., Chionchio, G., Di Lellis, A., Marcucci, M. F., Pallocchia, G., Korth, A., Daly, P. W., Graeve, B., Rosenbauer, H., Vasyliunas, V., McCarthy, M., Wilber, M., Eliasson, L., Lundin, R., Olsen, S., Shelley, E. G., Fuselier, S., Ghielmetti, A. G., Lennartsson, W., Escoubet, C. P., Balsiger, H., Friedel, R., Cao, J.-B., Kovrazhkin, R. A., Papamastorakis, I., Pellat, R., Scudder, J., and Sonnerup, B.: First multispacecraft ion measurements in and near the Earth's magnetosphere with the identical Cluster ion spectrometry (CIS) experiment, Ann. Geophys., 19, 1303-1354, 2001, http://www.ann-geophys.net/19/1303/2001/.
Shue, J., Song, P., Russell, C. T., Steinberg, J. T., Chao, J. K., Zastenker, G., Vaisberg, O. L., Kokubun, S., Singer, H. J., Detman, T. R., and Kawano, H.: Magnetopause location under extreme solar wind conditions, J. Geophys. Res., 103, 17691-17700, doi: 10.1029/98JA01103, 1998.

Strangeway, R., Ergun, R. E., Su, Y. J., Carlson, C. W., and Elphic, R. C.: Factors controlling ionospheric outflows as observed at intermediate altitudes, J. Geophys Res., 110, 3221, doi:10.1029/2004JA010829, 2005.

Su, Y.-J., Horwitz, J. L., Moore, T. E., Giles, B. L., Chandler, M. O., Craven, P. D., Hirahara, M., and Pollock, C. J.: Polar wind survey with the Thermal Ion Dynamics Experiment/Plasma Source Instrument suite aboard POLAR, J. Geophys. Res., 103, 2930529338, doi:10.1029/98JA02662, 1998.

Torkar, K., Riedler, W., Escoubet, C. P., Fehringer, M., Schmidt, R., Grard, R. J. L., Arends, H., Rüdenauer, F., Steiger, W., Narheim, B. T., Svenes, K., Torbert, R., André, M., Fazakerley, A., Goldstein, R., Olsen, R. C., Pedersen, A., Whipple, E., and Zhao, H.: Active spacecraft potential control for Cluster - implementation and first results, Ann. Geophys., 19, 1289-1302, 2001, http://www.ann-geophys.net/19/1289/2001/. 